\title{
Functional beta diversity of New Zealand fishes: Characterising morphological turnover along depth and latitude gradients, with derivation of functional bioregions
}

\author{
ELISABETH M. V. MYERS, ${ }^{* 1}$ (D) DAVID EME, ${ }^{1,2}$ (D) LIBBY LIGGINS, ${ }^{3,4}$ (D) \\ EUAN S. HARVEY, ${ }^{6}$ (D) CLIVE D. ROBERTS ${ }^{5}$ AND MARTI J. ANDERSON ${ }^{1}$ \\ ${ }^{1}$ New Zealand Institute for Advanced Study (NZIAS), Massey University, Albany Campus, Auckland, \\ 0745, New Zealand (Email: lizzymyers90@gmail.co); ${ }^{2}$ Unité Ecologie et Modèles pour l'Halieutique, \\ IFREMER, Nantes, France; ${ }^{3}$ School of Natural and Computational Sciences (SNCS), Massey \\ University, Auckland, New Zealand; ${ }^{4}$ Auckland Museum, Tāmaki Paenga Hira, Auckland, New \\ Zealand; ${ }^{5}$ Museum of New Zealand Te Papa Tongarewa, Wellington, New Zealand; and ${ }^{6}$ School of \\ Molecular and Life Sciences, Curtin University, Bentley, Western Australia, Australia
}

\begin{abstract}
Changes in the functional structures of communities are rarely examined along multiple large-scale environmental gradients. Here, we describe patterns in functional beta diversity for New Zealand marine fishes versus depth and latitude, including broad-scale delineation of functional bioregions. We derived eight functional traits related to food acquisition and locomotion and calculated complementary indices of functional beta diversity for 144 species of marine ray-finned fishes occurring along large-scale depth (50-1200 $\mathrm{m}$ ) and latitudinal gradients $\left(29^{\circ}-51^{\circ} S\right)$ in the New Zealand Exclusive Economic Zone. We focused on a suite of morphological traits calculated directly from in situ Baited Remote Underwater Stereo-Video (stereo-BRUV) footage and museum specimens. We found that functional changes were primarily structured by depth followed by latitude, and that latitudinal functional turnover decreased with increasing depth. Functional turnover among cells increased with increasing depth distance, but this relationship plateaued for greater depth distances $(>750 \mathrm{~m})$. In contrast, functional turnover did not change significantly with increasing latitudinal distance at $700-1200 \mathrm{~m}$ depths. Shallow functional bioregions $(50-100 \mathrm{~m}$ ) were distinct at different latitudes, whereas deeper bioregions extended across broad latitudinal ranges. Fishes in shallow depths had a body shape conducive to efficient propulsion, while fishes in deeper depths were more elongated, enabling slow, energy-efficient locomotion, and had large eyes to enhance vision. Environmental filtering may be a primary driver of broad-scale patterns of functional beta diversity in the deep sea. Greater environmental homogeneity may lead to greater functional homogeneity across latitudinal gradients at deeper depths (700-1200 m). We suggest that communities living at depth may follow a 'functional village hypothesis', whereby similar key functional niches in fish communities may be maintained over large spatial scales.
\end{abstract}

Key words: beta diversity, deep-sea fishes, functional homogeneity, spatial turnover, trait.

\section{INTRODUCTION}

A primary goal of ecology is to understand the distribution of species and their interactions, often in relation to an environmental gradient. Beta diversity measures the variation in species composition among locations or sites, and provides a link between regional (gamma, $\gamma$ ) and local (alpha, $\alpha$ ) diversity (Whittaker 1960; Whittaker 1972). It has been used to address key questions in ecology such as what makes communities more similar or different, or to understand how the magnitude of those differences vary along spatial or temporal gradients (Vellend 2001; Anderson et al. 2011). One aspect of beta diversity, referred to as

*Corresponding author.

Accepted for publication April 2021. 'turnover', measures changes in assemblages of species along a predefined gradient, which can be geographical (e.g. distance), or environmental (e.g. moisture, salinity or depth). Here, we use the word 'turnover' in its broader sense (sensu Nekola \& White 1999; Anderson et al. 2011), and not in the more specific sense defined in the context of partitioning beta diversity into turnover and nestedness components (see Baselga 2010; Baselga 2012; Villéger et al. 2013). Turnover has been used to define the scale over which species and communities change in response to variations in environmental conditions along large spatial gradients (Kraft et al. 2011). Understanding turnover in communities can help to define the breaks between biogeographic regions, and to denote the spatial areas over which communities and their constituent species are similar (Ficetola et al. 2017). 
Traditionally, patterns in beta diversity have been investigated using taxonomic approaches (e.g. to measure turnover in the composition of species; Anderson et al. 2011) which treat all species as equivalent (as per the functional equivalence hypothesis; Hubbell, 2001). This fails to recognize, however, that different species have different trophic positions, feeding strategies, dispersal capacities and biomass, hence are inherently functionally different. Some species, however, can be functionally very similar and may perform similar ecological roles (e.g. in the deep sea an eel and a rattail or grenadier fish may both be scavengers), while others can be functionally very different (e.g. a small herbivorous wrasse vs. a large predatory shark). Changes in functional composition, therefore, are not necessarily directly proportional to changes in species composition (Villéger et al. 2012; McLean et al. 2019). For example, Mouton et al. (2020) found that certain freshwater macroinvertebrate communities became taxonomically more homogeneous, yet functionally more heterogeneous, in response to changes in climate. In contrast, McLean et al. (2019) documented marine fish communities in the North Sea over a period of warming climate becoming increasingly more functionally similar, even though, taxonomically, communities diverged (McLean et al. 2019).

Functional diversity has been studied within particular regions (Swenson \& Weiser 2014; Pigot et al. 2016; McLean et al. 2019), but there is a limited understanding of functional turnover along largescale spatial gradients, particularly in the ocean (Stuart-Smith et al. 2013; Mindel et al. 2016). Environmental conditions can change dramatically along large-scale spatial gradients such as depth or latitude, and extreme conditions may filter out organisms lacking the required functional strategies for survival (Kraft et al. 2011). Ultimately, the way that organisms survive in a particular abiotic and biotic environment is mediated through their functional traits (Calow, 1987; Cadotte et al. 2011). Understanding functional dissimilarities among communities along large gradients can provide powerful insights into the potential mechanisms underlying community assembly, the potential role of selection, dispersal traits and associated processes (e.g. Swenson et al. 2011; Siefert et al. 2013; Swenson 2014). For example, Weinstein et al. (2014) found that high taxonomic beta diversity in hummingbird communities was due to geographic barriers to dispersal associated with elevation, while, simultaneously, trait beta diversity was low, due to similar traits occurring across geographically isolated habitats that had similar environmental conditions.

In addition, functional diversity can be used to delineate functional bioregions or identify functional 'hotspots'. These may differ, however, from taxonomic hotspots, and both may be of interest in the preservation of multiple facets of biodiversity (Mouillot et al. 2011; Pollock et al. 2020). Functional redundancy among species' traits can lead to a decoupling of taxonomic and functional diversity (Mouillot et al. 2014). For example, several studies discovered a spatial incongruence between taxonomic and functional diversity hotspots for marine fishes (Mouillot et al. 2011; Stuart-Smith et al. 2013; Guilhaumon et al. 2015), leading to questions regarding the efficacy of current preservation areas to protect overall biodiversity (Pollock et al. 2017, 2020). Previously, taxonomic and phylogenetic beta diversity have been used to delineate bioregions of homogeneous communities and identify transition zones (i.e. biogeographic barriers, Kreft \& Jetz, 2010; Holt et al. 2013; Ficetola et al. 2017). Investigating functional beta diversity can allow functionally homogeneous bioregions and transition zones with high functional turnover to be identified, which can, in turn, help to inform conservation planning (Pollock et al. 2020). It can also provide a baseline against which the potential impacts of future environmental changes on ecological functions may be measured (McLean et al. 2019). Presently, however, we lack a clear understanding of how the distribution of species and communities along environmental gradients is mediated by their functional traits (but see Sunday et al. 2015; Marzloff et al. 2018), which limits our ability to delineate functional bioregions and functional transition zones, and to infer potential mechanisms of community assembly. Such a knowledge gap is made even more profound in marine systems due to the dearth of studies on functional turnover, especially along the depth gradient.

The depth gradient is a major spatial gradient for which patterns of beta diversity are largely unknown due to vast swathes of the ocean remaining virtually unexplored (McClain \& Rex 2015). The deep sea is the largest habitat on earth; it is well connected and environmentally buffered (Ramirez-Llodra et al. 2010). Generally, as habitat is thought to become more homogeneous with increasing depth, communities tend to become more similar across large (latitudinal) spatial scales at deeper depths (as indicated by studies of taxonomic beta diversity for: Asteroidea, Price et al. 1999; bivalves, McClain and Rex, 2015; and fishes, Zintzen et al. 2011, Anderson et al. 2013, Zintzen et al. 2017).

Marine fishes account for over half of all vertebrate diversity and are widespread latitudinally (Rabosky et al. 2018) and along the depth gradient (Yancey et al. 2014; Priede, 2017). Fishes have huge morphological diversity (Wainwright \& Longo, 2017), and carry out key ecosystem processes such as nutrient cycling and controlling food webs (Villéger et al. 2017). Previous studies have described a decline in both alpha and beta diversity of fish communities 
with increasing depth (Zintzen et al. 2011, 2017; Anderson et al. 2013). It has been hypothesised that environmental conditions at deep depths in the ocean may filter out all but a specific subset of fish species that are able to survive in these relatively extreme conditions, and these species tend to be widely distributed in cold, connected and relatively homogeneous habitat covering large areas (Priede, 2017). A recent study suggested that the functional alpha diversity for fishes (based on their morphological traits) remains relatively stable to a depth of $\sim 1200 \mathrm{~m}$, while functional distances among individuals within communities increases with depth (Myers et al. 2021). These results run counter to the classical ecological paradigm that functions are filtered more strongly in harsh environments than in benign environments (Swenson et al. 2011). However, changes in community-level functional beta diversity along the depth gradient for fishes has yet to be documented.

Our overarching goal was to document broad-scale functional turnover in a marine ecosystem. This will provide baseline biogeographic patterns against which future changes may be compared, allowing hypotheses regarding the potential processes shaping communities to be refined, and to inform better management decisions to protect the functional diversity of fishes.

Here, we describe patterns of functional beta diversity for assemblages of marine ray-finned fishes along large-scale depth $(50-1200 \mathrm{~m})$ and latitudinal $\left(29^{\circ}-\right.$ $51^{\circ} \mathrm{S}$ ) gradients in New Zealand waters. We focused on the multivariate functional space defined by a suite of morphological traits for locomotion and food acquisition, calculated directly from measurements of individual fishes, to identify areas of functional homogeneity and transition zones. First, we modelled the relationship between the functional dissimilarities in fish communities versus absolute differences in either depth or latitude (Nekola \& White 1999; Millar et al. 2011). Contrary to patterns documented for taxonomic beta diversity of fishes versus depth (Anderson et al. 2013), we hypothesised that the slopes of these relationships would be steeper for the depth gradient than for the latitude gradient because environmental constraints with increasing depth are expected to be greater than with increasing latitude. However, we also hypothesised that latitudinal functional turnover would decrease with increasing depth, which would be consistent with patterns previously described for taxonomic turnover (Anderson et al. 2013; Zintzen et al. 2017). We consider that departures from these proposed null hypotheses will indicate the influence of unacknowledged processes shaping the communities based on the functions of food acquisition and locomotion. Next, we quantified functional turnover between adjacent (neighbouring) depth-by-latitude cells to identify the specific position (s) along each gradient at which abrupt functional changes occur. Finally, we used clustering and ordination tools to propose 'functional bioregions' and transition zones for New Zealand's fish assemblages that could help to inform conservation planning.

\section{METHODS}

\section{Fish community data}

Baited Remote Underwear Stereo-Video systems (StereoBRUVs) were used to sample marine ray-finned fishes (Class Actinopterygii) in situ at off-shore locations across northern, eastern and southern New Zealand (see Zintzen et al. 2012, 2017 for detailed positions). The StereoBRUVs were deployed in a stratified random sampling design at each of seven depths (50, 100, 300, 500, 700, 900 and $1200 \mathrm{~m}$ ) within each of seven locations (from north to south): Rangitāhua, the Kermadec Islands (KER), Three Kings Islands (TKI), Great Barrier Island (GBI), Whakaari, White Island (WI), Kaikōura (KKA), Otago Peninsula (OTA) and the Auckland Islands (AUC) that spanned $21^{\circ}$ of latitude in New Zealand waters (with $n=5-7$ replicate deployments per depth-by-location, see Figure 1 from Zintzen et al. 2017 for a detailed map showing exact sampling locations). Video footage was obtained from a total of 329 deployments ( $2 \mathrm{~h}$ each) across 47 depth-by-location cells ( 2 cells were not sampled - White Island at $1200 \mathrm{~m}$ and Auckland Islands at $1200 \mathrm{~m}$, due to poor weather conditions). For further details regarding the sampling design, the Stereo-BRUV apparatus and deployment, calibration of measurements and associated methodologies, see Zintzen et al. (2012, 2017).

\section{Functional traits}

Fifteen raw morphological measurements were obtained from individuals of each species of fish, in situ, by reviewing footage obtained from each Stereo-BRUV deployment and using the software 'EventMeasure' (www.seagis.com.au; see Myers et al. (2021) and Appendix S1: Table S1). Where possible, measurements from multiple individuals of a single species within a given depth-by-location cell were obtained. A complete set of morphological measurements were not always possible to obtain for every species observed in the video footage. For individuals that were missing no more than 3 (out of 15) measurements, the missing values were imputed using a random-forest machine-learning algorithm (Stekhoven \& Bühlmann 2012), based on the other individuals of that species in the dataset having a complete set of measurements. This imputation relies on the assumption that relationships among the morphological variables remain constant within a given species. In addition, to ensure we would have a full set of measured traits for every fish species, we also took raw morphological measurements directly from two preserved museum specimens (held within the National Fish Collection at the Museum of New Zealand Te Papa Tongarewa, 

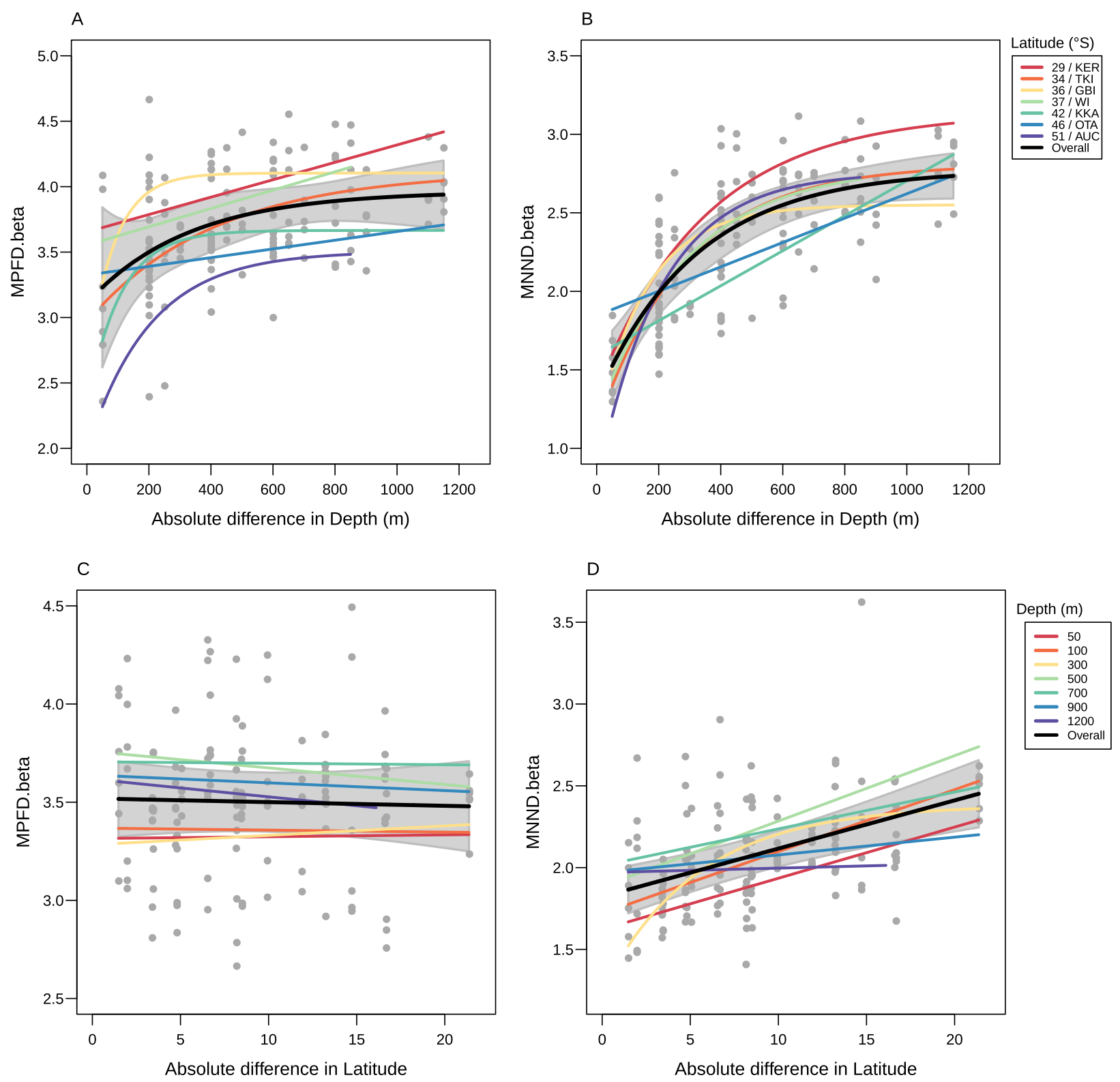

Fig. 1. Relationship between functional turnover in the morphology of fishes, measured as either MPFD.beta or MNND.beta versus absolute differences in depth $(a, b)$ or absolute differences in latitude (c, d). Coloured lines show the individual fitted models within each latitude $(a, b)$ or within each depth stratum (c, d). Black lines show the best overall fitted model, with a $95 \%$ confidence region (shaded grey) obtained using the delta method, given estimated variances in parameters obtained using a jack-knife procedure, as described in Millar et al. (2011). See Tables 1 and 2 in the text and the Appendix S2 for further details regarding fitted models.

Wellington) for every species seen in the video footage (voucher registrations are provided in Appendix S1: Table S2). In total, there were 144 species recorded across the 47 depth-by-location cells, and 509 species-by-cell occurrences. The original dataset comprised a complete set of 15 raw morphological measurements for 722 individuals observed in video footage (136 of these required some random-forest imputation, and missing traits were remeasured for 4 individuals), plus 291 museum specimens.

We calculated eight trait variables, namely: eye size, oral gape position, jaw length relative to head length, elongation, eye position, caudal peduncle throttling, pectoral fin position and total body length - each as a function of the 15 raw morphological measurements (2 of the raw morphological measurements were used only for data imputation, Appendix S1: Table S3). These morphological traits focused on key aspects of locomotion, visual perception and feeding for fishes that correspond to important functional variations in the body plan and structure of fishes across large depth gradients (Myers et al. 2019).

We obtained representative trait values for every species within every cell in the study design, while taking into 
account the intraspecific trait variability. To do so we compiled a table of 8 unique traits (columns) for each species in each depth-by-location cell (509 rows), we randomly drew 1 individual from the list of all complete individuals for each species that were (in order of preference): (i) within that depth-by-location cell, (ii) at the same depth, (iii) from anywhere within the Stereo-BRUV study design or (iv) from a museum specimen. We replicated this random-draw procedure 100 times to generate 100 speciescell $\times$ trait $(509 \times 8)$ data tables. These data tables enabled us to build 100 multivariate functional spaces based on the 8 normalised continuous trait variables that were used to compute the Euclidean distances between species. By calculating beta diversity values for all 100 tables, then averaging these values, we were able to integrate the available individual-level (within-species) morphological variation into the study, given the logistic constraints on the number of individuals of each species we were able to measure, while also maintaining spatial variation in morphologies encountered within each species as well as possible.

\section{Measures of functional beta diversity}

We calculated the functional turnover, or functional beta diversity, by considering the functional distances between each of the species occurring within one cell, with every species occurring within another cell (Swenson 2014). We calculated the following metrics between every pair of cells: (i) mean pairwise functional distance (MPFD.beta) which corresponds in the beta context to the mean distance in functional space between all pairs of species across two cells (Swenson 2014), and (ii) mean nearest-neighbour distance (MNND.beta) which corresponds in the beta context to the average of the minimum functional distance between each species in one cell, to every species in another cell (Swenson \& Weiser 2014). Previously, MPFD has been defined in an alpha context as the functional analogue to average taxonomic distinctness (Clarke \& Warwick 1998), and is also called mean phylogenetic pairwise distance (Swenson 2014) when used in a phylogenetic context. MNND, also called Gamma+ (Clarke et al. 2006), has been used previously in both phylogenetic (Webb et al. 2002) and functional contexts (Swenson \& Weiser 2014; Pigot, Trisos \& Tobias 2016) where it has been used to estimate functional originality (Mouillot et al. 2013; Leitao et al. 2016), and can be considered as an indicator of differences in niche (Swenson et al. 2020). These two functional beta diversity metrics allow the full dimensionality of the functional space to be entirely maintained, which is not necessarily possible with earlier-described metrics, such as convex hulls (Villéger et al. 2013), or hypervolumes (Blonder et al. 2014, 2018). These typically require a rather drastic reduction in dimensionality, especially for species-poor communities such as those encountered in the deep sea.

We calculated the MPFD.beta and MNND.beta metrics between every pair of cells for each of the 100 species-cell by trait $(509 \times 8)$ data matrices, then computed the mean and standard deviation across the 100 tables for subsequent analyses. The result was a $47 \times 47$ matrix of functional dissimilarities (either MPFD.beta or MNND.beta) among all pairs of cells in our study design.

\section{Functional turnover versus depth and latitude}

We modelled functional turnover (MPFD.beta or MNND.beta) as a response variable $\left(d_{Y}\right)$ versus absolute differences in either depth (in hundreds of meters) or latitude (decimal degrees) as a predictor variable $\left(d_{X}\right)$. We expected measures of functional turnover generally to increase with increasing distances between samples along a gradient of interest (depth or latitude), potentially reaching an asymptote. Thus, for each turnover measure, we fitted: (i) a twoparameter least-squares linear model (i.e. an intercept and a linear slope parameter); and (ii) an adapted vonBertalanffy growth model (see the Appendix S2) - a threeparameter nonlinear exponential curve which approaches an asymptote. The best of these two potential models was chosen using a small-sample-corrected AIC criterion (AICc), and the (simpler) linear model was retained whenever the two models were deemed (via AICc) to be effectively equivalent $\left(\Delta \mathrm{AIC}_{C}<2 \times\left(\frac{n_{d}}{n_{d}-q-1}\right)\right.$, where $n_{d}$ is the number of values of $d_{Y}$ and $q$ is the number of parameters in the von-Bertalanffy model). Individual points in these models are not independent of one another (both $d_{Y}$ and $d_{X}$ arise from structured inter-point distance matrices). Thus, the statistical significance of each relationship was tested using a non-parametric Mantel test of the rank correlation (Spearman's $\rho$ ) between $d_{Y}$ and $d_{X}$, using the RELATE routine in PRIMER $v 7$ (Clarke \& Gorley 2015), and standard errors on parameters were estimated using a jack-knife procedure, as in Millar et al. (2011).

In addition to the overall models, separate models were fitted to visualise: (i) functional turnover versus depth at each of the seven latitudes; and (ii) functional turnover versus latitude for each depth stratum. We also plotted turnover (MPFD.beta or MNND.beta) between adjacent cells along either the depth or the latitude gradient, in order to identify particular depths and/or latitudes at which 'breaks' in functional space might occur.

\section{Functional distinctness and comparison with null models}

We assessed observed versus expected functional distinctness using the TAXDTEST routine in PRIMER 7 (Clarke \& Gorley 2015). TAXDTEST is usually used to calculate average taxonomic distinctness, but in this case was adapted to calculate the functional analogue 'average functional distinctness', as suggested by Somerfield et al. (2008). The average functional distinctness of a depth-bylatitude cell is the average functional distance among all pairs of species in the cell, and can be considered the average functional breadth of a sample (also known as mean pairwise functional distance, MPFD). Note that, whereas taxonomic distinctness uses a taxonomic tree to calculate distances among species, it is possible also to perform the calculations using a functional (or other) distance matrix among species instead (see Bevilacqua et al. 2021, this volume). We performed the TAXDTEST algorithm separately for each depth stratum, using a normalised Euclidean distance matrix based on the 8 functional traits averaged across the dataset at the species level $(n=144)$. Specifically, we considered a null model that the functional 
distinctness obtained for the list of species observed in a given cell was within the bounds of what would be expected for that depth stratum, given the number of species observed in that cell (Clarke \& Warwick 1998). Thus, we generated $95 \%$ confidence bounds for the expected functional distinctness for a given number of species (from 3 species to 35 species) using 1000 random draws from the full list of species seen within each depth stratum (e.g. $50 \mathrm{~m}$ ) across the entire study design. We also considered the frequency of the species within each depth stratum when performing the null model approach (See Appendix S1: Fig. S4).

\section{Functional bioregions}

To visualise functional turnover across the entire study design, we produced a non-metric multi-dimensional scaling (nMDS; Kruskal \& Wish 1978) ordination plot based on functional dissimilarities between all pairs of depth-bylatitude cells. This was achieved using PRIMER v7 (Clarke \& Gorley 2015), which allows any distance matrix among species to be used in the calculation of resemblances among samples. Because we used functional distances among the species based on the 8 normalised traits, rather than a taxonomic tree, our 'taxonomic resemblances' (called 'Gammat' in PRIMER, see Clarke et al. 2006) were actually functional resemblances (or, rather, dissimilarities in the form of MNND.beta) in our analysis. We used Gamma+/MNND.beta and MPFD.beta metrics to create the nMDS plot; however, because MNND.beta showed stronger trends with differences in depth and latitude (see Results), subsequent analyses focused only on MNND.beta. In addition, a two-way crossed nonparametric ANOSIM test of the two ordered factors of depth and latitude (see Somerfield et al. 2021b) was done on the basis of this functional resemblance matrix. This tested the null hypothesis that there was no ordered pattern of functional turnover along each gradient, independently of any potential changes along the other gradient. For further details regarding non-parametric tests of ordered changes in community structure along gradients, see Somerfield et al. (2002) and Somerfield et al. (2021a) (this volume). For details of two-way ANOSIM tests on ordered factors, see Clarke et al. (2014) and Somerfield et al. (2021b).

To classify New Zealand's fish assemblages into biogeographic groups of cells containing sets of species that collectively possess a similar suite of functional strategies/morphologies, we used $k-R$ clustering (Clarke et al. 2016) on the functional (Gamma+ or MNND.beta) resemblance matrix among the depth-by-latitude cells. We performed sequential non-hierarchical $k-R$ cluster analyses for choices of $k$ from 2 up to 10 clusters. The algorithm was stopped when similarity profile tests (SIMPROF, see Clarke et al. 2008; Somerfield \& Clarke 2013; Clarke et al. 2014) indicated that no further splitting into a larger number of clusters was justifiable (i.e. when there was not sufficient structure within any of the resulting $k-R$ cluster groupings to generate a statistically significant SIMPROF test-statistic). This generated $k=7$ groups of cells, which we shall refer to as 'functional bioregions'. For each functional bioregion, we identified the individual fish species lying closest to the centroid (in 8-dimensional trait space) to provide a visual exemplar of a typical morphological body plan for fish occurring in each group.

\section{RESULTS}

\section{Functional turnover versus depth and latitude}

Functional turnover in fish communities, as measured by MPFD.beta, was greater along the depth gradient than along the latitudinal gradient (Fig. 1a, c; Tables 1 and 2). The slope of the relationship between functional dissimilarity and differences in depth was steeper for smaller absolute differences in depth (50-300 m) and was also steeper when measured using nearest-neighbour distances (MNND. beta, Fig. 1b, Table 1). Generally, MPFD.beta and MNND.beta plateaued at absolute differences in depth of $\sim 750 \mathrm{~m}$ or more, indicating limits to functional turnover in fish communities overall. In addition, southern latitudes generally had lower values of MPFD.beta and MNND.beta than northern latitudes (i.e. a smaller intercept).

Strikingly, the mean pairwise functional distance (MPFD.beta) between fish communities did not increase significantly with increasing latitudinal distance (the relationships remained non-significant for all depth strata; Table 2). Thus, functional dissimilarities appear not to be related to changes in latitude. In addition, intermediate depths (500-700 m) consistently had the largest functional latitudinal turnover (i.e. high intercepts, see Table 2A), followed by deep (900-1200 m) and shallow (50-300 m) depths (Fig. 1c). In contrast, MNND.beta did increase with increasing latitudinal distance although the relationship weakened at deeper depths (Fig. 1d). At the deepest depths (900-1200 m), there were no significant increases in functional turnover of fish communities with increasing spatial distance (Table 2).

Peaks in turnover among adjacent depth cells depended on latitude (Appendix S1: Fig. S2). For example, the greatest functional turnover was between 50 and $100 \mathrm{~m}$ for KER and WI (Appendix S1: Fig. S2A), whereas GBI showed the highest turnover between 500 and $700 \mathrm{~m}$, and southern locations (e.g. AUC) showed very low functional turnover at shallow depths $(50-100 \mathrm{~m}$ or $100-300 \mathrm{~m}$; Appendix S1: Fig. S2A). However, functional turnover from 900 to $1200 \mathrm{~m}$ was very similar (MPFD.beta 3.5) for all latitudes (Appendix S1: Fig. S2A). Similarly, turnover among adjacent latitudinal bands was depth dependent. Interestingly, for both MPFD.beta and MNND.beta, the greatest 
FUNCTIONAL $\beta$ DIVERSITY OF NEW ZEALAND FISHES

Table 1. Fitted models of functional turnover ( $d_{Y}$, measured as either (A) MPFD.beta or (B) MNND.beta), versus absolute differences in depth $\left(d_{X}\right.$ in hundreds of $\left.\mathrm{m}\right)$

\begin{tabular}{|c|c|c|c|c|c|}
\hline & Best model & Fitted Model Parameters & $\rho$ & $P$ & Sig. \\
\hline \multicolumn{6}{|l|}{ (A) MPFD.beta } \\
\hline All & von-Bert. & $L_{\infty}=3.965 ; L_{0}=3.110 ; K=0.304$ & 0.547 & 0.0001 & $* * *$ \\
\hline $\mathrm{KER}, 29^{\circ} \mathrm{S}$ & Linear & $\beta_{0}=3.654 ; \beta_{1}=0.067$ & 0.698 & 0.0040 & $* *$ \\
\hline $\mathrm{TKI}, 34^{\circ} \mathrm{S}$ & von-Bert. & $L_{\infty}=4.116 ; L_{0}=2.966 ; K=0.242$ & 0.643 & 0.0065 & $* *$ \\
\hline $\mathrm{GBI}, 36^{\circ} \mathrm{S}$ & von-Bert. & $L_{\infty}=4.104 ; L_{0}=2.579 ; K=1.178$ & 0.112 & 0.2963 & ns \\
\hline WI, $37^{\circ} \mathrm{S}$ & Linear & $\beta_{0}=3.553 ; \beta_{1}=0.070$ & 0.601 & 0.0180 & $*$ \\
\hline $\mathrm{KKA}, 42^{\circ} \mathrm{S}$ & von-Bert. & $L_{\infty}=3.666 ; L_{0}=2.312 ; K=0.940$ & 0.874 & 0.0005 & $* * *$ \\
\hline OTA, $46^{\circ} \mathrm{S}$ & Linear & $\beta_{0}=3.324 ; \beta_{1}=0.033$ & 0.361 & 0.0867 & $\mathrm{~ns}$ \\
\hline AUC, $51^{\circ} \mathrm{S}$ & von-Bert. & $L_{\infty}=3.505 ; L_{0}=1.986 ; K=0.493$ & 0.543 & 0.0338 & $*$ \\
\hline \multicolumn{6}{|c|}{ (B) MNND.beta } \\
\hline All & von-Bert. & $L_{\infty}=2.775 ; L_{0}=1.315 ; K=0.311$ & 0.721 & 0.0001 & $* * *$ \\
\hline $\mathrm{KER}, 29^{\circ} \mathrm{S}$ & von-Bert. & $L_{\infty}=3.139 ; L_{0}=1.363 ; K=0.284$ & 0.885 & 0.0006 & $* * *$ \\
\hline $\mathrm{TKI}, 34^{\circ} \mathrm{S}$ & von-Bert. & $L_{\infty}=2.809 ; L_{0}=1.127 ; K=0.350$ & 0.777 & 0.0002 & $* * *$ \\
\hline GBI, $36^{\circ} \mathrm{S}$ & von-Bert. & $L_{\infty}=2.551 ; L_{0}=1.133 ; K=0.609$ & 0.467 & 0.0301 & $*$ \\
\hline WI, $37^{\circ} \mathrm{S}$ & von-Bert. & $L_{\infty}=2.801 ; L_{0}=1.190 ; K=0.343$ & 0.865 & 0.0037 & $* *$ \\
\hline $\mathrm{KKA}, 42^{\circ} \mathrm{S}$ & Linear & $\beta_{0}=1.590 ; \beta_{1}=0.111$ & 0.806 & 0.0006 & $* * *$ \\
\hline OTA, $46^{\circ} \mathrm{S}$ & Linear & $\beta_{0}=1.845 ; \beta_{1}=0.078$ & 0.542 & 0.0242 & $*$ \\
\hline AUC, $51^{\circ} \mathrm{S}$ & von-Bert. & $L_{\infty}=2.759 ; L_{0}=0.782 ; K=0.479$ & 0.702 & 0.0153 & * \\
\hline
\end{tabular}

The models were either a linear regression model: $E\left(d_{Y}\right)=\beta_{0}+\beta_{1} d_{X}$, or an adapted nonlinear von-Bertalanffy growthcurve model (see the Appendix S2): $E\left[d_{Y}\right]=L_{\infty}-\left(L_{\infty}-L_{0}\right) \times \exp \left(-K d_{X}\right)$. An overall model ('All') was fitted, followed by separate individual models for each location. The best model was chosen using an AICc criterion, and statistical significance was tested using a non-parametric RELATE test, using Spearman's rank matrix correlation ( $\rho$ ), and with $P$-values obtained using 9999 random permutations of the original latitude-by-site cells. Levels of significance ('Sig.') are denoted using asterisks: $P<0.0001\left(^{* * *}\right) ; P<0.01\left(^{* *}\right) ; P<0.05\left(^{*}\right)$; and $P>0.05$ (ns).

Table 2. Fitted models of functional turnover ( $d_{Y}$, measured as either (A) MPFD.beta or (B) MNND.beta), versus absolute differences in latitude $\left(d_{X}\right.$ in decimal degrees)

\begin{tabular}{|c|c|c|c|c|c|}
\hline & Best model & Fitted Model Parameters & $\rho$ & $P$ & Sig. \\
\hline \multicolumn{6}{|c|}{ (A) MPFD.beta } \\
\hline All & Linear & $\beta_{0}=3.519 ; \beta_{1}=-0.002$ & -0.052 & 0.6905 & ns \\
\hline $50 \mathrm{~m}$ & Linear & $\beta_{0}=3.315 ; \beta_{1}=0.001$ & -0.031 & 0.5149 & ns \\
\hline $100 \mathrm{~m}$ & Linear & $\beta_{0}=3.368 ; \beta_{1}=-0.001$ & -0.179 & 0.7331 & ns \\
\hline $300 \mathrm{~m}$ & Linear & $\beta_{0}=3.283 ; \beta_{1}=0.005$ & 0.030 & 0.4899 & ns \\
\hline $500 \mathrm{~m}$ & Linear & $\beta_{0}=3.759 ; \beta_{1}=-0.008$ & -0.018 & 0.4840 & ns \\
\hline $700 \mathrm{~m}$ & Linear & $\beta_{0}=3.706 ; \beta_{1}=-0.001$ & 0.186 & 0.2304 & ns \\
\hline $900 \mathrm{~m}$ & Linear & $\beta_{0}=3.638 ; \beta_{1}=-0.004$ & -0.105 & 0.6264 & ns \\
\hline $1200 \mathrm{~m}$ & Linear & $\beta_{0}=3.622 ; \beta_{1}=-0.009$ & -0.248 & 0.7438 & ns \\
\hline \multicolumn{6}{|c|}{ (B) MNND.beta } \\
\hline All & Linear & $\beta_{0}=1.822 ; \beta_{1}=0.029$ & 0.426 & 0.0001 & $* * *$ \\
\hline $50 \mathrm{~m}$ & Linear & $\beta_{0}=1.622 ; \beta_{1}=0.031$ & 0.512 & 0.0199 & $*$ \\
\hline $100 \mathrm{~m}$ & Linear & $\beta_{0}=1.720 ; \beta_{1}=0.038$ & 0.640 & 0.0067 & $* *$ \\
\hline $300 \mathrm{~m}$ & von-Bert. & $L_{\infty}=2.382 ; L_{0}=1.250 ; K=0.185$ & 0.797 & 0.0005 & $* *$ \\
\hline $500 \mathrm{~m}$ & Linear & $\beta_{0}=1.884 ; \beta_{1}=0.040$ & 0.468 & 0.0269 & $*$ \\
\hline $700 \mathrm{~m}$ & Linear & $\beta_{0}=2.012 ; \beta_{1}=0.022$ & 0.426 & 0.0490 & * \\
\hline $900 \mathrm{~m}$ & Linear & $\beta_{0}=1.969 ; \beta_{1}=0.011$ & 0.305 & 0.1322 & ns \\
\hline $1200 \mathrm{~m}$ & Linear & $\beta_{0}=1.968 ; \beta_{1}=0.003$ & -0.164 & 0.7122 & ns \\
\hline
\end{tabular}

The models were either a linear regression model: $E\left[d_{Y}\right]=\beta_{0}+\beta_{1} d_{X}$, or an adapted nonlinear von-Bertalanffy growthcurve model (see the Appendix S2): $E\left[d_{Y}\right]=L_{\infty}-\left(L_{\infty}-L_{0}\right) \times \exp \left(-K d_{X}\right)$. An overall model ('All') was fitted, followed by separate individual models for each depth stratum. The best model was chosen using an AICc criterion, and statistical significance was tested using a non-parametric RELATE test, using Spearman's rank matrix correlation $(\rho)$, and with $P$-values obtained using 9999 random permutations of the original latitude-by-site cells. Levels of significance ('Sig.') are denoted using asterisks: $P<0.0001\left(^{* * *}\right) ; P<0.01\left(^{* *}\right) ; P<0.05\left(^{*}\right)$; and $P>0.05$ (ns). 
functional turnover between adjacent latitudes occurred at mid-to-deep depths of 500, 700 and $900 \mathrm{~m}$, particularly at northern locations between TKI, GBI and WI (Appendix S1: Fig. S2C,D).

\section{Functional distinctness and comparison with null models}

Observed values of functional distinctness generally fell within the $95 \%$ bounds of expected values generated from lists of species observed within each depth stratum, although many fell below the mean (midline 3.8) (Appendix S1: Fig. S3). AUC however, generally had lower than expected functional distinctness, consistently falling outside, or on the lower bounds of the funnel across all depth strata. At shallower depths, KKA (50 and $100 \mathrm{~m}$ ) and TKI $(100 \mathrm{~m})$ also had lower-than-expected functional distinctness (Appendix S1: Fig. S3). Generally, northern locations such as KER or GBI had greater functional distinctness compared to other locations across all depths. Results based on null models accounting for the frequency of species within each depth stratum were qualitatively very similar (see Appendix S1: Fig. S4).

\section{Functional bioregions}

There was a clear trend of functional turnover in fish communities from shallow to deep environments for MNND.beta (i.e. from left to right on the nMDS plot; Fig. 2a), that was more subtle when using MPFD.beta (Appendix S1: Fig. S5). MNND.beta showed a strong and significant pattern of sequential functional turnover in fish communities detected along the depth gradient (two-way ordered ANOSIM: $R=0.828, P=0.0001)$. Significant sequential functional turnover, although less strong, was also detected along the latitude gradient $(R=0.501$, $P=0.0001$ ), but was not apparent in the $2 \mathrm{~d}$ nMDS ordination plot (Fig. 2a).

The $k-R$ cluster routine performed on depth-bylatitude cells with SIMPROF tests identified seven groups. Cells within the same functional bioregion

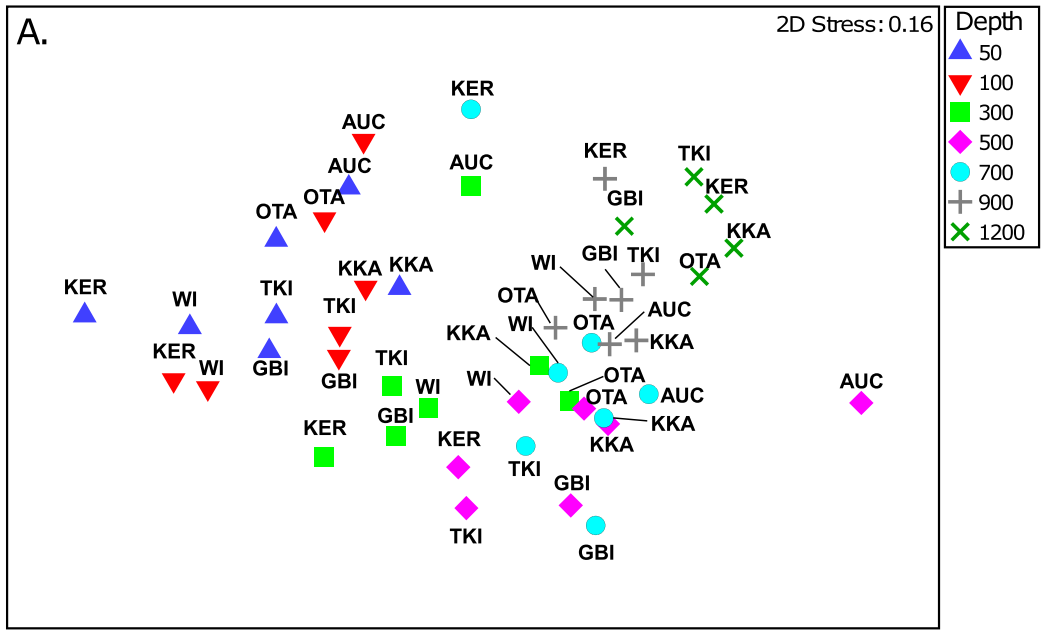

Fig. 2. Non-metric multidimensional scaling (nMDS) ordination on the basis of mean nearest-neighbour functional distances (the Gamma+ dissimilarity measure in PRIMER, or MNND.beta) among depthby-location cells for $P=8$ normalised functional traits, with symbols corresponding to (a) the 7 depth strata or (b) the 7 functional bioregions identified using unconstrained nonhierarchical $k-R$ partitioning and associated SIMPROF tests.

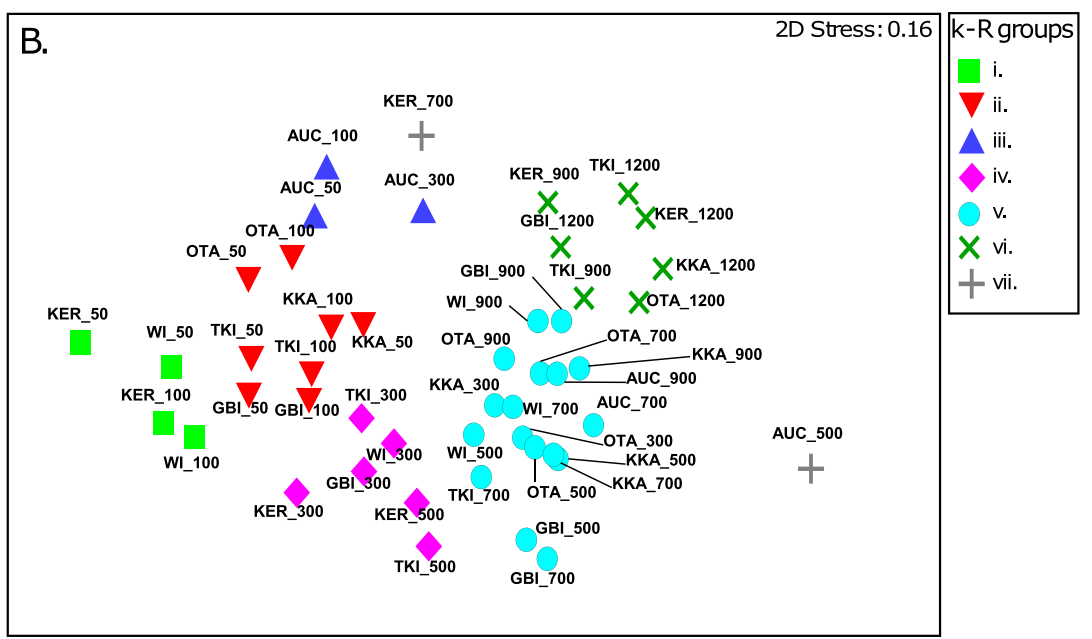




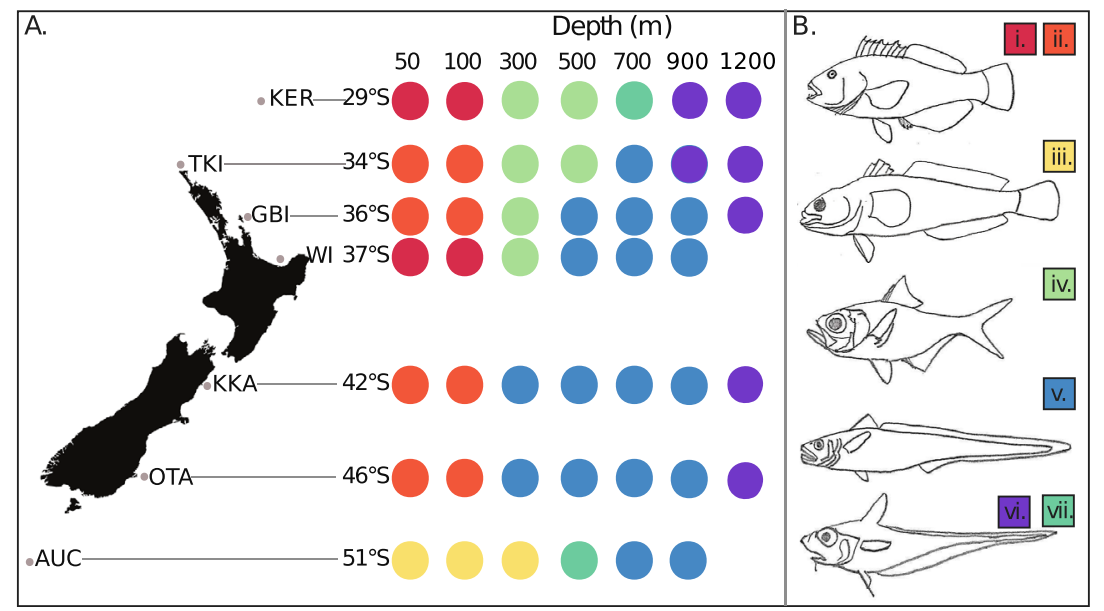

Fig. 3. (a) Schematic diagram of the cells in the study design belonging to each of the 7 functional bioregions (i)-(vii), denoted by seven colours, alongside a map of New Zealand. (b) A family-level representation of the fish species closest to the centroid in the 8-dimensional trait space (i.e. an 'arch-typical' species) for each functional bioregion, adapted from Roberts et al. (2015): (i) Bodianus unimaculatus, Labridae, (ii) Bodianus flavipinnis, Labridae, (iii) Notothenia microlepidota, Nototheniidae, (iv) Etelis coruscans, Lutjanidae, (v) Lyconnus pinnatus, Merluccidae, (vi) Coryphaenoides subserrulatus, Macrouridae, (vii) Lepidorhynchus denticulatus, Macrouridae. See Appendix S1: Fig. S1 for a photograph of each species.

possess fish species which broadly embrace a similar area of the eight-dimensional functional morphological trait-space investigated here. These seven functional bioregions were very clearly identified as coherent groups in the nMDS plot (Fig. 2b). Interestingly, the cells within the same cluster were generally spatially identifiable and contiguous (with few exceptions), even though no spatial constraints were imposed on the $k-R$ partitioning algorithm (Fig. 3).

Fish communities sampled from $50 \mathrm{~m}$ or $100 \mathrm{~m}$ at either KER or WI comprised the first group (i). Communities at shallow depths $(50-100 \mathrm{~m})$ in midlatitude locations (TKI, GBI, KKA and OTA) comprised a second group (ii), while shallow communities at AUC (from 50 - $300 \mathrm{~m}$ ) comprised a third group (iii). Intermediate depths were split into a northern $300 \mathrm{~m}$ to $500 \mathrm{~m}$ group (iv) and a larger, close-knit group ranging from predominantly southern $300-900 \mathrm{~m}$ depths (v). A deep group (vi) encompassed all fish communities sampled at $1200 \mathrm{~m}$ across all locations, plus those sampled at $900 \mathrm{~m}$ at the northern locations of KER and TKI (Fig. 2b; Fig. 3a). Finally, a seventh 'group' was comprised of two spatially disparate communities: $700 \mathrm{~m}$ at KER and $500 \mathrm{~m}$ at AUC (Fig. 3); however, these two cells were not highly similar to one another, but rather appeared to be individual and separate outliers on the nMDS plot (Fig. 2b).

The general change in fish morphology along the depth gradient showed a transition from deeper bodied fishes, with rounded, lunate or forked tails in shallow and intermediate depths to a more elongate, slender form with a tapering tail in deeper waters
(Fig. 3b; Fig. 4). Fishes that were closest to the centroid of the functional space were generally perciforms. Shallow groups (Fig. 4i,ii) tended to have similar morphologies (except group ii had a greater mean jaw to head-length ratio). Eye size was larger for intermediate and deep groups (Fig. 4iv-vii) and was particularly large relative to body length for fishes at KER_700 and AUC_500 (i.e. group vii). Elongation was generally highest and caudal peduncle throttling was lowest at intermediate and deep depths (Fig. 4v-vii), which is typical of deep-sea orders (Gadiformes, Notocanthiformes, Ophidiiformes and Anguilliformes).

\section{DISCUSSION}

We have provided a description of the patterns of functional beta diversity for a sample of New Zealand's marine ray-finned fishes across large-scale depth and latitudinal gradients, also characterising how the functional structure of communities varied according to key food acquisition and locomotion traits. We found that functional variation in fish communities was primarily structured by depth and then by latitude, and that fish communities generally became more functionally homogeneous (at least by reference to the traits we measured) with increasing depth. More specifically, functional turnover among cells increased with increasing depth distance, but this relationship plateaued at greater depth distances $(>750 \mathrm{~m})$. Functional turnover, as measured by MPFD.beta and MNND.beta, did not change 

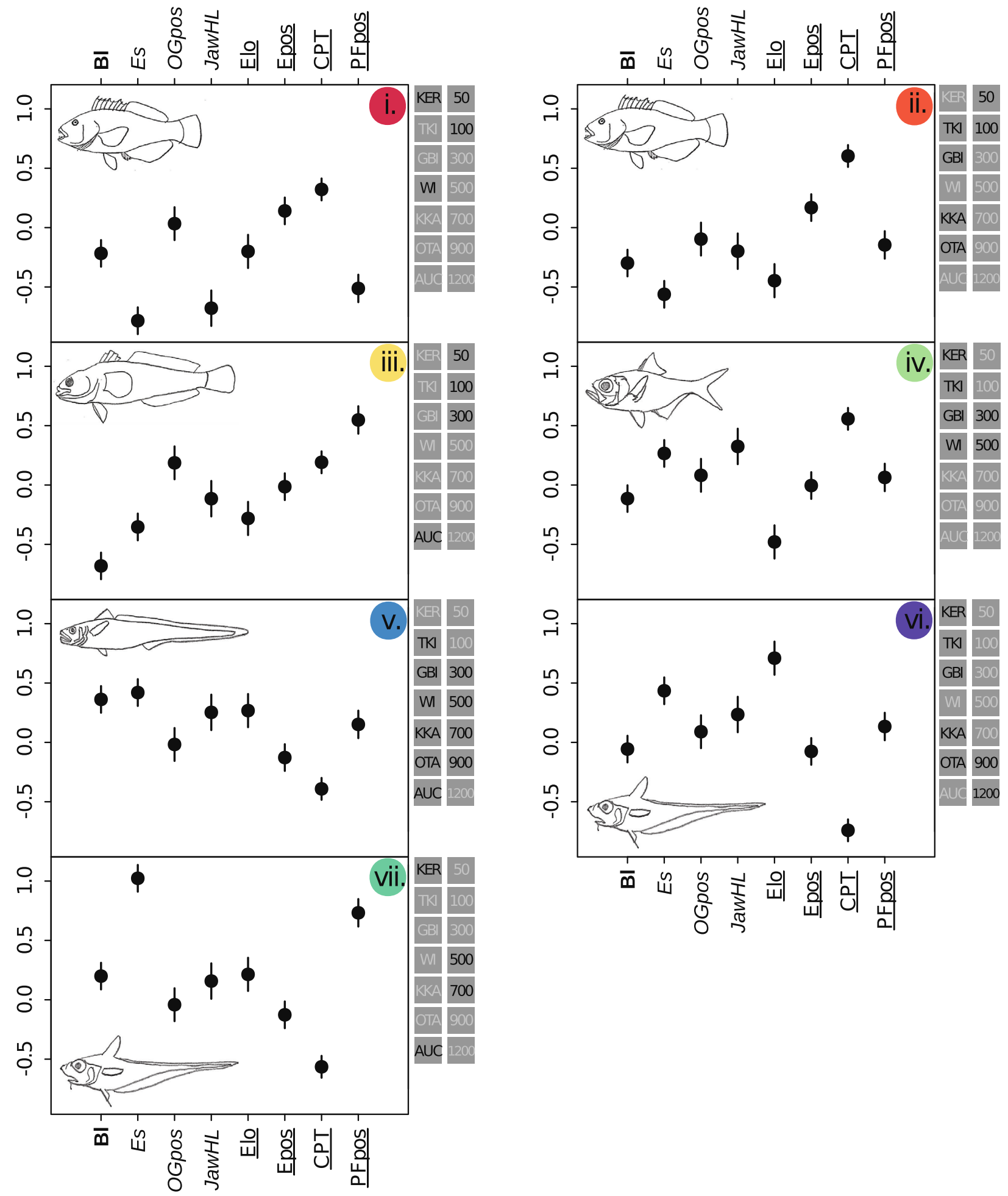

Fig. 4. Mean $\pm 1 \mathrm{SE}$ of the normalised functional trait values for fish species occurring within each functional bioregion (see Fig. 3). The y-axis scale is fixed for each plot to allow direct comparisons of mean trait values across the different plots. $B l$, body length; $C P T$, caudal peduncle throttling; Elo, elongation; Epos, eye position; Es, eye size; faw $H L$, jaw length as a proportion of head length; OGPos, oral gape position; PFpos, pectoral fin position. Number of fishes used to calculate the SE ranged from 14 (group iii) to 182 (group v). Trait abbreviations: bold represents a universal trait, italic represents a food acquisition trait, and underline represents a locomotion trait (see Appendix S1: Table S3 for a description of each trait). 
significantly with increasing latitudinal distance for depths between 700 and $1200 \mathrm{~m}$, suggesting that the environmental filtering of traits in the deep sea may lead to a certain degree of functional homogeneity among communities spread over large spatial scales. Abrupt changes in the functional structure of communities were latitude-dependent, and shallow, northern depth-by-latitude cells were most variable (MPFD.beta and MNND.beta), as were deeper, northern depth-by-latitude cells for MNND.beta. Most of the observed values of functional distinctness fell within the expected bounds generated under a null model for a particular targeted depth, and northern locations (KER and GBI) were generally more functionally distinct than southern locations (KKA and AUC), which occasionally had lower-thanexpected functional distinctness. Finally, functional bioregions in shallow depth strata $(50-100 \mathrm{~m})$ were further delineated according to latitude, whereas deeper bioregions consisted of groups of cells that occurred along broader extents of the latitudinal gradient. Fishes in the shallows (50-100 m) had a body shape that was more conducive to efficient propulsion (a high value for caudal peduncle throttling), important both for catching prey and for eluding predators (Webb 1984; Villéger et al. 2010), and a deep body for defence against gape-limited predators (Hodge et al. 2018). In contrast, fishes in deeper depths were more elongated, enabling slow, energyefficient swimming in low-resource environments and large eyes for dimly lit intermediate depths (Neat \& Campbell 2013; Myers et al. 2019).

Our most salient finding was that, the further apart two fish communities were along the depth gradient, the more functionally dissimilar they were (Fig. 1a, b). We found that the rate of functional turnover versus depth varied at different positions along the gradient; specifically, functional dissimilarity increased with increasing depth distance until $\sim 750 \mathrm{~m}$, and then plateaued. Functional beta diversity has previously been found to decline with increasing environmental (e.g. elevation; Swenson et al. 2011) or geographic (Siefert et al. 2013) distance in tropical (Puerto Rico) and temperate (North Eastern American) tree communities, respectively. In a taxonomic context, Anderson et al. (2013), also found an increase in turnover with depth distance up to a plateau around 600-800 $\mathrm{m}$ depth difference for NorthEast Pacific fishes.

Steep rates of functional turnover for smaller depth distances, measured using either average (MPFD.beta) or nearest-neighbour (MNND.beta) functional distance metrics, mirrored rates observed for taxonomic turnover across similar depth ranges (Anderson et al. 2013). These patterns may reflect strong environmental filtering acting on fishes' traits in specific regions/sections of the depth gradient. For example, the traits that enable survival at $50 \mathrm{~m}$ are likely very dissimilar to the traits enabling survival of fishes living at $700 \mathrm{~m}$ (e.g. see Myers et al. 2019). Changes in adapted traits along the depth gradient may well be reflected by differences in morphological characters that may have been used to define many of the fish species, genera and families. Thus, taxonomic and functional information would not be expected to be entirely independent, and this may explain the congruence of patterns observed for taxonomic and functional beta diversity versus depth. In addition, congruent patterns of taxonomic and functional turnover versus depth suggests that changes in taxonomic composition are mirrored by concomitant changes in the functional space (at least for the locomotion and food acquisition traits examined here).

Importantly, functional diversity patterns depend strongly on the traits measured, and thus are susceptible to change if additional traits documenting other functions are considered and included ( $\mathrm{Zhu}$ et al. 2017). The rapid changes that occur vertically along the increasing depth gradient across a host of important physical environmental parameters (such as decreasing light, temperature, dissolved oxygen, and food availability, along with increasing pressure; Priede, 2017), happen at fairly small to modest spatial scales (typically only spanning 100's of meters to kilometres) compared to the much larger spatial scale (100's of kilometres) of the latitude gradient investigated here. Nevertheless, over the deeper areas examined in our study (i.e. between $\sim 700-1200 \mathrm{~m}$ ), latitudinal functional turnover was low; the morphological traits of fishes (characterised, e.g. by an elongated body, a tapering tail and a large gape; Neat \& Campbell 2013; Myers et al. 2019) were likely similar at these depths regardless of latitude due to the relatively homogeneous habitat. In fact, turnover in functional traits between 50 and $700 \mathrm{~m}$ was similar in magnitude to that seen between 50 and $1200 \mathrm{~m} \mathrm{-}$ explaining the plateau in Figure 1a,b. Hence, functional turnover for fishes with depth depended on the specific position along the depth gradient being considered, and was likely influenced by the rate of environmental change along the depth gradient, which also may differ among locations (see Appendix S1: Fig. S2).

In contrast to patterns of functional turnover along the depth gradient, our functional metrics MPFD.beta and MNND.beta demonstrated two different types of response along the latitudinal gradient. MPFD.beta, which is heavily influenced by species that are functionally divergent, showed little change with increasing latitudinal distance (Table 2 A). This suggests that, within each depth stratum, species separated by large functional distances (i.e. that are functionally divergent) effectively occur across all of the communities sampled within a given 
depth stratum along the entire length of the latitudinal gradient. This may be a result of functionally convergent species at the extreme ends of the latitudinal gradient carrying out similar functions, regardless of their taxonomic or phylogenetic relationships. For example, Tebbett et al. (2020) found that a key function - macroalgal removal - was carried out by a surgeon fish (Naso unicorus) on the Great Barrier Reef, and a trigger fish (Melicthys niger) in the Caribbean, suggesting that key convergent and highly similar functional roles can traverse both large classical taxonomic and large biogeographic distances.

In contrast, a significant linear increase of MNND.beta (Table 2B) was observed along the latitudinal gradient. This may indicate that the 'closest functional neighbour' of fishes (i.e. having a similar functional strategy) tends to become increasingly dissimilar with larger geographic (latitudinal) distance. Interestingly, the increasing average value of MNND.beta with increasing latitudinal distance became flatter (and non-significant) for deeper depth strata (700-1200m; Fig. 1d); the relatively high nearest-neighbour distances remained fairly constant among deeper fish communities. We considered that this pattern (which also occurred for MPFD.beta) might be explained by a functional trait version of the 'ecological village hypothesis' developed by Smith et al. (2014), which suggests that, across regions with similar environmental characteristics, a full collection of essential ecological roles will be represented, yielding taxonomic similarity at the family level (but not necessarily at the species level) across large spatial scales. We suggest that this may also be happening in the deep sea; that is, due to homogeneous environmental conditions, the functional analogues to 'a butcher, a baker, and a candlestick maker' (perhaps a gelativore, a scavenger, and a piscivore; Drazen \& Sutton 2017) are sampled repeatedly across large spatial scales. This may contribute to the stable latitudinal functional turnover (beta diversity) at deeper depths for MNND.beta, and across all depths for MPFD.beta. The functional organisation of fishes may be intrinsically linked to not only the environmental characteristics of habitats at large spatial scales, but also the fine-scale ecological linkages among coexisting organisms within their niches. Although functional turnover across latitude was relatively low for deeper depth strata, the intercept, (i.e. the expected functional dissimilarity among fishes within a given cell), was higher for deeper depth strata than for shallow depth strata. Whilst the deeper communities were species poor, the broad repetition of co-occurring fishes from orders such as Anguilliformes (eels) and Gadiformes (rattails) was relatively common. We suggest that for communities containing only a handful of species, the high values of MNND.beta may be driven by the co-occurrence of relatively ubiquitous and functionally similar species (e.g. from Anguilliformes and Gadiformes) along with rarer, and functionally different species from a different order (for example, Ruvettus pretiosus order Scombriformes) in different latitudes. The MNND.beta metric will be sensitive to variations in the combination of frequent (and functionally 'common') species versus infrequent (functionally 'unique') species.

Functionally distinct regions of the ocean, such as the tropical eastern Pacific Ocean (Grenié et al. 2018), hold many species that have distinct functional traits. We questioned whether the observed functional beta diversity at a given depth was higher or lower than expected given a random draw from the broader species list under a null model of random species assembly within a given depth stratum. We found that southern latitudes generally had lower-than-expected functional distinctness, particularly AUC and KKA in shallow (50-100 m) depths (Appendix S1: Fig. S3A,B). This may indicate that the environmental filtering of traits in a homogeneous habitat (as shown in Smith \& Wilson 2002), and consistent, stable environmental conditions has led to convergent functional communities (Swenson et al. 2012; Siefert et al. 2013; Pinto-Ledezma et al. 2018). We found no depth-by-latitude cells with higher-than-expected functional distinctness, although communities at northern latitudes (KER, GBI) were generally more functionally distinct than southern latitudes (AUC, KKA). This may be tied to higher species richness at northern locations, and a greater diversity of habitats (Shears et al. 2008; Zintzen et al. 2012; Zintzen et al. 2017).

We found that functional turnover was stronger along the depth gradient than along the latitude gradient, but that functional bioregions were delineated spatially by a combination of both gradients. The largest group of depth-by-latitude cells was a large cluster spanning intermediate and deep depths across the full length of the latitudinal gradient investigated here (group v; Fig. 3a), indicating that the ecological strategies associated with food acquisition and locomotion of fishes in this bioregion are largely homogeneous at these depths. A similar large spatial cluster was also found on the basis of phylogenetic diversity metrics for the same community dataset (see Eme et al. 2020), suggesting that the functional traits examined here might retain a strong phylogenetic signal. Functional bioregions in shallower depths were partitioned into three different groups according to latitude (groups i-iii; Fig. 3a). Knowledge of functional distinctiveness, turnover and bioregions can be used along with taxonomic and phylogenetic measures of diversity (e.g. Eme et al. 2020) to help designate areas of marine protection in order to protect regional biodiversity in a broader and more 
ecologically relevant manner (Stuart-Smith et al. 2013). In addition, boundaries corresponding to transition zones between functional bioregions may provide ideal places to monitor over time in order to detect major biogeographic shifts in fish communities in response to anthropogenic change.

Turnover in fish morphology with increasing depth towards a body shape that is functionally convergent across latitude suggests that environmental filtering is an important force of selection acting on fishes' traits. A transition in fish body plans from a deeperbodied morphology with a rounded or forked tail in shallower depths, to an elongate body shape with a tapering tail at deeper depths has been described by Neat and Campbell (2013) and Myers et al. (2019). This pattern, taken with the plateau of functional turnover in the deep (Fig. 1), suggests that the environmental filtering of traits in the deep sea is a key process structuring this community. Convergence of the elongate anguilliform body shape across multiple different orders (e.g. Ophidiiformes, Gadiformes, Notocanthiformes and Aulopiformes) also indicates that this body shape has led to success for fishes in the deep sea (Priede, 2017). This widespread body form may also contribute to the low levels of functional turnover observed in the deep sea, with a variety of different taxonomically distinct fishes potentially fulfilling quite similar functions across large swathes of the study design. Environmental constraints at depth are likely to select for good dispersers with energy-efficient locomotion and opportunistic feeding strategies (Myers et al. 2019). These traits are often associated with a wide distribution, especially in a homogeneous environment with scarce trophic resources that may require fish to travel over large distances to forage (Priede, 2017). The selection of convergent traits adapted to the deep sea would, as a by-product, yield decreases in both taxonomic (Anderson et al. 2013; Zintzen et al. 2017) and functional beta diversity to generate homogeneous functional bioregions over large latitudinal distances (this study).

Our study has provided the first quantification of how functional beta diversity varies for fishes along the large-scale environmental gradients of depth and latitude, adding an important baseline understanding to the understudied deep sea. Functional turnover was stronger with depth than with latitude, and latitudinal functional turnover remained stable at deeper depths. Some of these patterns were mirrored in earlier studies of taxonomic turnover (Anderson et al. 2013; Zintzen et al. 2017), suggesting that taxonomic and functional diversity are not independent of one another, at least considering the set of morphological traits measured here. Patterns in functional diversity depend strongly on the traits examined ( $\mathrm{Zhu}$ et al. 2017), inviting us to consider our results as provisional. Future studies should examine and include other traits, such as key life-history, physiological, and behavioural traits (Bellwood et al. 2019). Measuring traits that can be used specifically to detect species' responses to climate-related environmental change would be advantageous, such as size and growth rate, as well as key indicators of habitat use, such as thermal preference and water-column position (McLean et al. 2019). Furthermore, understanding how the turnover of functional traits covary with environmental variables (such as temperature, dissolved organic matter and particulate organic carbon) will yield additional insight into the potential mechanistic processes structuring functional diversity in communities (Wieczynski et al. 2019). Additionally, studying a greater depth range would help extend models of functional turnover versus depth. Finally, we emphasise that the boundaries of functional bioregions (and the species typifying each bioregion) may be constantly shifting under globalscale environmental change. Quantifying temporal changes in functional beta diversity will help clarify the impacts of important future ecological changes on ecosystem functioning (Pinto-Ledezma et al. 2018; McLean et al. 2019).

\section{CONCLUSION}

In the face of cumulative anthropogenic impacts such as climate change, overfishing, pollution and deepsea mining, ensuring the future health of the deep ocean requires an understanding of both current conditions and rates of change in the biodiversity of marine ecosystems (Danovaro et al. 2020). Here we have provided the first description of patterns of functional beta diversity for fishes along large-scale depth and latitude gradients in New Zealand waters, and have delineated broad-scale functional bioregions for fishes based on these patterns. Representative sites from each functional bioregion, particularly from multiple areas showing higher functional turnover (i.e. shallow-to-intermediate depths), should be prioritized for protection in order to ensure a variety of assemblages supporting many different functional traits will be conserved (Socolar et al. 2016). We have also proposed a 'functional village hypothesis', a natural extension of the 'ecological village hypothesis' (Smith et al. 2014), and consider that repetition of the same key biological functions making up a 'village' (i.e. a community) may contribute to stable and functionally similar ecosystems in the deep sea over large spatial distances. Overall, documenting the trends in large-scale patterns of functional beta diversity for marine fishes has allowed us to: (i) set-up baseline patterns to test for potential functional homogenization in the future that may be caused by global 
changes in marine ecosystems; (ii) delineate biogeographic transition zones that could serve as important areas to monitor for change; and (iii) locate regions/ depths containing key or unique functional traits that, if protected, may act as reservoirs of essential functions in order to maintain fundamental ecosystem processes.

\section{ACKNOWLEDGEMENTS}

This work was funded by the Royal Society of New Zealand Te Apārangi (RSNZ), Marsden Grant 15-MAU-132. E. Myers was also supported by a Sir Hugh Kawharu Scholarship, and a Te Pūtea Whakatupu Trust Rona Scholarship. We thank Andrew Stewart, Carl Struthers, Jeremy Barker and Salme Kortet (Museum of New Zealand Te Papa Tongarewa) and Tom Trnski and Severine Hannam (Auckland Museum, Tāmaki Paenga Hira) for their support of this research and access to museum fish collections. We would also like to thank Bob Clarke for his invaluable contributions to the field of marine biodiversity and are incredibly honoured to have the opportunity to be involved in such a special issue.

\section{AUTHOR CONTRIBUTION}

Elisabeth Myers: Conceptualization (equal); Data curation (lead); Formal analysis (equal); Investigation (lead); Methodology (equal); Project administration (lead); Validation (equal); Visualization (lead); Writing-original draft (lead); Writing-review \& editing (lead). David Eme: Conceptualization (equal); Formal analysis (equal); Investigation (equal); Methodology (equal); Supervision (equal); Writing-review \& editing (equal). Libby Liggins: Conceptualization (equal); Funding acquisition (supporting); Investigation (equal); Supervision (equal); Writing-review \& editing (equal). Euan Harvey: Supervision (supporting). Clive Roberts: Data curation (equal); Funding acquisition (supporting); Resources (equal); Supervision (equal); Writing-review \& editing (equal). Marti J. Anderson: Conceptualization (equal); Formal analysis (equal); Funding acquisition (lead); Investigation (equal); Methodology (equal); Project administration (equal); Resources (equal); Software (equal); Supervision (lead); Validation (equal); Visualization (equal); Writing-review $\&$ editing (equal).

\section{DATA AVAILABILITY STATEMENT}

The data used in this study are deposited in the Dryad Digital Repository https://doi.org/10.5061/ dryad.tdz08kq0d (Myers et al. (2021)).

\section{REFERENCES}

Anderson M. J., Crist T. O., Chase J. M. et al. (2011) Navigating the multiple meanings of $\beta$ diversity: a roadmap for the practicing ecologist. Ecol. Lett. 14, 19-28.

Anderson M. J., Tolimieri N. \& Millar R. B. (2013) Beta diversity of demersal fish assemblages in the North-Eastern Pacific: interactions of latitude and depth. PLoS One 8, e57918.

Baselga A. (2010) Partitioning the turnover and nestedness components of beta diversity. Global Ecol. Biogeogr. 19, 134-43.

Baselga A. (2012) The relationship between species replacement, dissimilarity derived from nestedness, and nestedness. Global Ecol. Biogeogr. 21, 1223-32.

Bellwood D. R., Streit R. P., Brandl S. J. \& Tebbett S. B. (2019) The meaning of the term 'function' in ecology: a coral reef perspective. Funct. Ecol. 33, 948-61.

Bevilacqua S., Anderson M. J., Ugland K. I., Somerfield P. J. \& Terlizzi A. (2021). The use of taxonomic relationships among species in applied ecological research: Baseline, steps forward and future challenges. Austral Ecol. http:// dx.doi.org/10.1111/aec.13061

Blonder B., Lamanna C., Violle C. \& Enquist B. J. (2014) The n-dimensional hypervolume. Global Ecol. Biogeogr. 23, 595-609.

Blonder B., Morrow C. B., Maitner B. et al. (2018) New approaches for delineating n-dimensional hypervolumes. Methods Ecol. Evol. 9, 305-19.

Cadotte M. W., Carscadden K. \& Mirotchnick N. (2011) Beyond species: functional diversity and the maintenance of ecological processes and services. F. Appl. Ecol. 48, 1079-87.

Calow P. (1987) Towards a definition of functional ecology. Funct. Ecol. 1, 57-61.

Clarke K. R. \& Gorley R. N. (2015) PRIMER v7: User Manual/Tutorial, 3rd edn. PRIMER-E, Plymouth.

Clarke K. R., Gorley R. N., Somerfield P. J. \& Warwick R. M. (2014) Change in Marine Communities: An Approach to Statistical Analysis and Interpretation, 3rd edn. PRIMER-E, Plymouth.

Clarke K. R., Somerfield P. J. \& Chapman M. G. (2006) On resemblance measures for ecological studies, including taxonomic dissimilarities and a zero-adjusted Bray-Curtis coefficient for denuded assemblages. F. Exp. Mar. Biol. Ecol. 330, 55-80.

Clarke K. R., Somerfield P. J. \& Gorley R. N. (2008) Testing of null hypotheses in exploratory community analyses: similarity profiles and biota-environment linkage. f. Exp. Mar. Biol. Ecol. 366, 56-69.

Clarke K. R., Somerfield P. J. \& Gorley R. N. (2016) Clustering in non-parametric multivariate analyses. $\mathcal{F}$. Exp. Mar. Biol. Ecol. 483, 147-55.

Clarke K. R. \& Warwick R. M. (1998) A taxonomic distinctness index and its statistical properties. f. Appl. Ecol. 35, 523-31.

Danovaro R., Fanelli E., Aguzzi J. et al. (2020) Ecological variables for developing a global deep-ocean monitoring and conservation strategy. Nature Ecol. Evol. 4, 181-92.

Drazen J. C. \& Sutton T. T. (2017) Dining in the deep: the feeding ecology of deep-sea fishes. Ann. Rev. Mar. Sci. 9, 337-66.

Eme D., Anderson M. J., Myers E., Roberts C. D. \& Liggins L. (2020) Phylogenetic measures reveal eco-evolutionary 
drivers of biodiversity along a depth gradient. Ecography 43, 1-14.

Ficetola G. F., Mazel F. \& Thuiller W. (2017) Global determinants of zoogeographical boundaries. Nat. Ecol. Evol. 1, 1-7.

Grenié M., Mouillot D., Villéger S. et al. (2018) Functional rarity of coral reef fishes at the global scale: Hotspots and challenges for conservation. Biol. Conserv. 226, 288-99.

Guilhaumon F., Albouy C., Claudet J. et al. (2015) Representing taxonomic, phylogenetic and functional diversity: new challenges for Mediterranean marineprotected areas. Diversity Distrib. 21, 175-87.

Hodge J. R., Alim C., Bertrand N. G. et al. (2018) Ecology shapes the evolutionary trade-off between predator avoidance and defence in coral reef butterflyfishes. Ecol. Lett. 21, 1033-42.

Holt B. G., Lessard J. P., Borregaard M. K. et al. (2013) An update of Wallace's zoogeographic regions of the world. Science 339, 74-8.

Hubbell S. P. (2001) The Unified Neutral Theory of Biodiversity and Biogeography. Princeton University Press, Princeton.

Kraft N. J., Comita L. S., Chase J. M. et al. (2011) Disentangling the drivers of $\beta$ diversity along latitudinal and elevational gradients. Science 333, 1755-8.

Kreft H. \& Jetz W. (2010) A framework for delineating biogeographical regions based on species distributions. $\mathcal{F}$. Biogeogr. 37, 2029-53.

Kruskal J. B. \& Wish M. (1978) Multidimensional Scaling. Sage Publications, London.

Leitao R. P., Zuanon J., Villéger S. et al. (2016) Rare species contribute disproportionately to the functional structure of species assemblages. Proc. Biol. Sci. 283, 20160084.

Marzloff M. P., Oliver E. C., Barrett N. S. et al. (2018) Differential vulnerability to climate change yields novel deep-reef communities. Nat. Clim. Change 8, 873-8.

McClain C. R. \& Rex M. A. (2015) Toward a conceptual understanding of $\beta$-diversity in the deep-sea benthos. Annu. Rev. Ecol. Evol. Syst. 46, 623-42.

McLean M., Mouillot D., Lindegren M. et al. (2019) Fish communities diverge in species but converge in traits over three decades of warming. Global Change Biol. 25, 397284.

Millar R. B., Anderson M. J. \& Tolimieri N. (2011) Much ado about nothings: using zero similarity points in distancedecay curves. Ecology 92, 1717-22.

Mindel B. L., Neat F. C., Trueman C. N., Webb T. J. \& Blanchard J. L. (2016) Functional, size and taxonomic diversity of fish along a depth gradient in the deep sea. Peerf 4, e2387.

Mouillot D., Albouy C., Guilhaumon F. et al. (2011) Protected and threatened components of fish biodiversity in the Mediterranean Sea. Curr. Biol. 21, 1044-50.

Mouillot D., Graham N. A., Villéger S., Mason N. W. \& Bellwood D. R. (2013) A functional approach reveals community responses to disturbances. Trends Ecol. Evol. 28, 167-77.

Mouillot D., Villeger S., Parravicini V. et al. (2014) Functional over-redundancy and high functional vulnerability in global fish faunas on tropical reefs. Proc. Natl. Acad. Sci. USA $111,13757-62$.

Mouton T. L., Tonkin J. D., Stephenson F., Verburg P. \& Floury M. (2020) Increasing climate-driven taxonomic homogenization but functional differentiation among river macroinvertebrate assemblages. Global Change Biol. 26, 6904-15.
Myers E. M., Anderson M. J., Eme D., Liggins L. \& Roberts C. D. (2019) Changes in key traits versus depth and latitude suggest energy-efficient locomotion, opportunistic feeding and light lead to adaptive morphologies of marine fishes. F. Anim. Ecol. 89, 309-22.

Myers E. M. V., Anderson M. J., Liggins L., Harvey E. S., Roberts C. D. \& Eme D. (2021) High functional diversity in deep-sea fish communities, and increasing intra-specific trait variation with increasing latitude. Ecol. Evol. http:// dx.doi.org/10.1002/ece3.7871

Myers E., Eme D., Liggins L., Harvey E. S., Roberts C. D. \& Anderson M. J. (2021) Functional beta diversity of New Zealand fishes: characterising morphological turnover along depth and latitude gradients, with derivation of functional bioregions. Dryad, Dataset. https://doi.org/10. 5061/dryad.tdz08kq0d

Neat F. \& Campbell N. (2013) Proliferation of elongate fishes in the deep sea. F. Fish Biol. 83, 1576-91.

Nekola J. C. \& White P. S. (1999) The distance decay of similarity in biogeography and ecology. F. Biogeogr. 26, 867-78.

Pigot A. L., Trisos C. H. \& Tobias J. A. (2016) Functional traits reveal the expansion and packing of ecological niche space underlying an elevational diversity gradient in passerine birds. Proc. Biol. Sci. 283, 20152013.

Pinto-Ledezma J. N., Larkin D. J. \& Cavender-Bares J. (2018) Patterns of beta diversity of vascular plants and their correspondence with biome boundaries across North America. Front. Ecol. Evol. 6, 194.

Pollock L. J., O'Connor L. M. J., Mokany K., Rosauer D. F., Talluto M. V. \& Thuiller W. (2020) Protecting biodiversity (in all its complexity): new models and methods. Trends Ecol Evol. 35, 1119-28.

Pollock L., Thuiller W. \& Jetz W. (2017) Large conservation gains possible for global biodiversity facets. Nature 546, $141-4$.

Price A., Keeling M. \& O'callaghan C. (1999) Ocean-scale patterns of 'biodiversity' of Atlantic asteroids determined from taxonomic distinctness and other measures. Biol. $\mathcal{F}$. Linn. Soc. 66, 187-203.

Priede I. G. (2017) Deep-sea Fishes: Biology, Diversity, Ecology and Fisheries. Cambridge University Press, Cambridge.

Rabosky D. L., Chang J., Title P. O. et al. (2018) An inverse latitudinal gradient in speciation rate for marine fishes. Nature 559, 392-5.

Ramirez-Llodra E., Brandt A., Danovaro R. et al. (2010) Deep, diverse and definitely different: unique attributes of the world's largest ecosystem. Biogeosciences 7, 2851-99.

Roberts C. D., Stewart A. L. \& Struthers C. D. (2015) The Fishes of New Zealand. Te Papa Press, Wellington.

Shears N. T., Smith F., Babcock R. C., Duffy C. A. \& Villouta E. (2008) Evaluation of biogeographic classification schemes for conservation planning: application to New Zealand's coastal marine environment. Conserv. Biol. 22, 467-81.

Siefert A., Ravenscroft C., Weiser M. D. \& Swenson N. G. (2013) Functional beta-diversity patterns reveal deterministic community assembly processes in eastern North American trees. Global Ecol. Biogeogr. 22, 682-91.

Smith B. \& Wilson J. B. (2002) Community convergence: ecological and evolutionary. Folia Geobot. 37, 171-83.

Smith H. L., Anderson M. J., Gillanders B. M. \& Connell S. D. (2014) Longitudinal variation and effects of habitat on biodiversity of Australasian temperate reef fishes. $\mathcal{F}$. Biogeogr. 41, 2128-39. 
Socolar J. B., Gilroy J. J., Kunin W. E. \& Edwards D. P. (2016) How should beta-diversity inform biodiversity conservation? Trends Ecol. Evol. 31, 67-80.

Somerfield P. J. \& Clarke K. R. (2013) Inverse analysis in nonparametric multivariate analyses: distinguishing groups of associated species which covary coherently across samples. f. Exp. Mar. Biol. Ecol. 449, 261-73.

Somerfield Paul J., Clarke K. Robert, Gorley Ray N. (2021) A generalised analysis of similarities (ANOSIM) statistic for designs with ordered factors. Austral Ecology, http://dx.doi. org/10.1111/aec.13043.

Somerfield Paul J., Clarke K. Robert, Gorley Ray N. (2021) Analysis of similarities (ANOSIM) for 2-way layouts using a generalised ANOSIM statistic, with comparative notes on Permutational Multivariate Analysis of Variance (PERMANOVA). Austral Ecology, http://dx.doi.org/10. 1111/aec.13059.

Somerfield P. J., Clarke K. \& Olsgard F. (2002) A comparison of the power of categorical and correlational tests applied to community ecology data from gradient studies. F. Anim. Ecol. 71, 581-93.

Somerfield P. J., Clarke K. R., Warwick R. M. \& Dulvy N. K. (2008) Average functional distinctness as a measure of the composition of assemblages. ICES F. Mar. Sci. 65, 1462-8.

Stekhoven D. J. \& Bühlmann P. (2012) MissForest - nonparametric missing value imputation for mixed-type data Bioinformatics 28, 112-8.

Stuart-Smith R. D., Bates A. E., Lefcheck J. S. et al. (2013) Integrating abundance and functional traits reveals new global hotspots of fish diversity. Nature 501, 539-42.

Sunday J. M., Pecl G. T., Frusher S. et al. (2015) Species traits and climate velocity explain geographic range shifts in an ocean-warming hotspot. Ecol. Lett. 18, 944-53.

Swenson N. G. (2014) Functional and Phylogenetic Ecology in R. Springer, New York.

Swenson N. G., Anglada-Cordero P. \& Barone J. A. (2011) Deterministic tropical tree community turnover: evidence from patterns of functional beta diversity along an elevational gradient. Proc. Biol. Sci. 278, 877-84.

Swenson N. G., Erickson D. L., Mi X. et al. (2012) Phylogenetic and functional alpha and beta diversity in temperate and tropical tree communities. Ecology 93(Suppl 8), S112-S125.

Swenson N. G., Hulshof C. M., Katabuchi M. \& Enquist B. J. (2020) Long-term shifts in the functional composition and diversity of a tropical dry forest: a 30-yr study. Ecol. Monogr. 90, e01408. https://doi.org/10.1002/ecm.1408

Swenson N. G. \& Weiser M. D. (2014) On the packing and filling of functional space in eastern North American tree assemblages. Ecography 37, 1056-62.

Tebbett S. B., Hoey A. S., Depczynski M., Wismer S. \& Bellwood D. R. (2020) Macroalgae removal on coral reefs: realised ecosystem functions transcend biogeographic locations. Coral Reefs 39, 203-14.

Vellend M. (2001) Do commonly used indices of $\beta$-diversity measure species turnover? F. Veg. Sci. 12, 545-52.

Villéger S., Brosse S., Mouchet M., Mouillot D. \& Vanni M. J. (2017) Functional ecology of fish: current approaches and future challenges. Aquat. Sci. 79, 783-801.

Villéger S., Grenouillet G. \& Brosse S. (2013) Decomposing functional $\beta$-diversity. Global Ecol. Biogeogr. 22, 671-81.

Villéger S., Miranda J. R., Hernández D. F. \& Mouillot D. (2010) Contrasting changes in taxonomy vs. functional diversity of tropical fish communities after habitat degradation. Ecol. Appl. 20, 1512-22.
Villéger S., Miranda J. R., Hernandez D. F. \& Mouillot D. (2012) Low functional $\beta$-diversity despite high taxonomic $\beta$-diversity among tropical estuarine fish communities. PLoS One 7, e40679.

Wainwright P. C. \& Longo S. J. (2017) Functional Innovations and the Conquest of the Oceans by Acanthomorph Fishes. Curr Biol. 27, 550-7.

Webb C. O., Ackerly D. D., McPeek M. A. \& Donoghue M. J. (2002) Phylogenies and community ecology. Annu. Rev. Ecol. Syst. 33, 475-505.

Webb P. W. (1984) Form and function in fish swimming. Sci. Am. 251, 72-83.

Weinstein B. G., Tinoco B., Parra J. L. et al. (2014) Taxonomic, phylogenetic, and trait beta diversity in South American Hummingbirds. Am. Nat. 184, 211-24.

Whittaker R. H. (1960) Vegetation of the Siskiyou mountains, Oregon and California. Ecol. Monogr. 30, 279-338.

Whittaker R. H. (1972) Evolution and measurement of species diversity. Taxon 21, 213-51.

Wieczynski D. J., Boyle B., Buzzard V. et al. (2019) Climate shapes and shifts functional biodiversity in forests worldwide. Proc. Natl. Acad. Sci. USA 116, 587-92.

Yancey P. H., Gerringer M. E., Drazen J. C., Rowden A. A. \& Jamieson A. (2014) Marine fish may be biochemically constrained from inhabiting the deepest ocean depths. Proc. Natl. Acad. Sci. USA 111, 4461-5.

Zhu L., Fu B., Zhu H., Wang C., Jiao L. \& Zhou J. (2017) Trait choice profoundly affected the ecological conclusions drawn from functional diversity measures. Sci. Rep. 7, 3643.

Zintzen V., Anderson M. J., Roberts C. D. \& Diebel C. E. (2011) Increasing variation in taxonomic distinctness reveals clusters of specialists in the deep sea. Ecography 34, 306-17.

Zintzen V., Anderson M. J., Roberts C. D., Harvey E. S. \& Stewart A. L. (2017) Effects of latitude and depth on the beta diversity of New Zealand fish communities. Sci. Rep. 7, 8081 .

Zintzen V., Anderson M. J., Roberts C. D., Harvey E. S., Stewart A. L. \& Struthers C. D. (2012) Diversity and composition of demersal fishes along a depth gradient assessed by baited remote underwater stereo-video. PLoS One 7, e48522.

\section{SUPPORTING INFORMATION}

Additional Supporting Information may/can be found online in the supporting information tab for this article.

Appendix S1. Raw morphological measurements and derived trait descriptions, museum voucher specimens, and statistical analyses.

Appendix S1. Table S1: Descriptions for each of fifteen morphological measurements obtained directly from individual fish observed in Baited Remote Underwater Stereo-Video (Stereo-BRUV) footage or museum specimens. Descriptions are adapted from Appendix A Villéger et al. (2010).

Appendix S1. Table S2: Museum voucher specimens of 144 New Zealand actinopterygian fish species examined. For each species there were between 1 and 4 individuals measured. See Roberts et al. (2015) for details of classification, nomenclature, 
distribution, and biology of each species. Specimens are listed in phylogenetic order, followed by a unique collection registration number. Prefix: AK and MA Auckland Museum Tāmaki Paenga Hira, The Domain, Parnell, Auckland; P - National Fish Collection, Museum of New Zealand Te Papa Tongarewa, 169 Tory Street, Wellington.

Appendix S1. Table S3: Description of 8 functional traits derived from raw morphological length measurements of individual fishes (see Appendix S1: Table S1).

Appendix S1. Fig. S1: Photographic images of the species closest to the centroid (in 8-dimensional functional trait-space (i.e. the 'typical' species morphology) for each functional bioregion (from Figs. 5 and 6). (i) Bodianus unimaculatus, Labridae, (ii) Bodianus flavipinnis, Labridae, (iii) Notothenia microlepidota, Nototheniidae, (iv) Etelis coruscans, Lutjanidae, (v) Lyconnus pinnatus, Merluccidae, (vi) Coryphaenoides subserrulatus, Macrouridae, (vii) Lepidorhynchus denticulatus, Macrouridae.

Appendix S1. Fig. S2: Functional turnover (measured by MPFD.beta or MNND.beta) between adjacent depth cells at each latitude (A, B; with coloured symbols denoting locations from KER in the north to AUC in the south), and between adjacent latitudinal cells within each depth stratum $(C, D$; with coloured symbols denoting depth strata from $50 \mathrm{~m}$ to $1200 \mathrm{~m})$. The error bars give the standard deviation in MPFD.beta or MNND.beta values calculated across the 100 data tables drawn randomly from the complete dataset.

Appendix S1. Fig. S3: Funnel plots showing mean (dotted line) and 95\% confidence bounds (solid lines) for the expected functional distinctness, given the number of species observed in each cell using random draws from the full list of species seen within each depth stratum. Coloured symbols show the observed functional distinctness values for each depth-by-latitude cell.

Appendix S1. Fig. S4: Funnel plots showing mean (dotted line) and 95\% confidence bounds (solid lines) for the expected functional distinctness observed in each cell using random draws from the full list of species seen within each depth stratum, given the frequency of the species within each depth stratum. Coloured symbols show the observed functional distinctness values for each depth-by-latitude cell.

Appendix S1. Fig. S5: Non-metric multi-dimensional scaling (nMDS) ordination on the basis of mean pairwise functional distances (MPFD.beta) among depth-by-location cells for $P=8$ normalised functional traits, with symbols corresponding to the 7 depth strata.

Appendix S2. Adaptation of the von Bertalanffy nonlinear growth curve for models of functional dissimilarities along spatial or environmental gradients. 